\title{
Responsabilidade das revistas científicas na proteção dos direitos dos sujeitos da pesquisa
}

\author{
Responsibility of scientific journals to protect the rights of research subjects
}

\begin{abstract}
Muito se tem evoluído na adoção de códigos de conduta e leis que tratam da garantia dos direitos humanos. Sobressaem-se nessa questão, os preceitos éticos que envolvem as pesquisas científicas. No Brasil, o marco regulatório foi a entrada em vigor da Resolução 196/96 do Conselho Nacional de Saúde. O respeito à ética e a proteção dos sujeitos envolvidos na pesquisa é, portanto, um ato humanitário e todas as instituições sociais devem zelar pelo seu cumprimento. As revistas científicas, que publicam e dão visibilidade aos resultados das pesquisas e dão notoriedade aos pesquisadores, têm grande responsabilidade no respeito aos cânones da ética.
\end{abstract}

Recentemente um grande pesquisador foi alvo de exposição na literatura científica por ter submetido à publicação uma série de estudos clínicos que, supostamente, não teriam sido aprovados por Comissão de Ética em Pesquisa. Isso significa violação de direitos dos sujeitos da pesquisa e, também, quebra de confiança.

Nada pode justificar tal ato no mundo atual. Iniciar uma pesquisa sem que o processo de submissão a uma Comissão de Ética em Pesquisa tenha se completado, com a obtenção da aprovação do estudo, se constitui em grave delito.

Recentemente, 18 editores de revistas científicas, principalmente de anestesia e terapia intensiva, se pronunciaram a respeito de 88 estudos clínicos de um mesmo autor realizados sem a aprovação de Comitê de Ética.

A magnitude dos prejuízos é difícil de estimar, mas certamente são extensos, uma vez que podem colocar em cheque a credibilidade das revistas científicas, além de apresentar impacto direto sobre o tratamento de pacientes. Algum tempo se levará até que a exposição pública desse problema tenha gerado as reparações necessárias. O prejuízo para a credibilidade da ciência é grande.

Algumas consequências desse episódio já se podem sentir como lições:

1- O amplo debate que se formou a partir do evento. Reuniões entre editores de revistas científicas e entre revisores e membros de conselhos editoriais têm debatido aspectos de como minimizar os prejuízos e como se evitar novas ocorrências. Recentemente, durante o Congresso Europeu de Anestesiologia, um amplo debate foi realizado, durante uma sessão científica entre editores e revisores de artigos científicos, que contou inclusive com a presença do editor da Revista Dor da SBED, Dr. Irimar de Paula Posso. Prevenir o desrespeito às normas éticas, por meio da educação e da fiscalização, é essencial e obrigatório;

2- A adoção, pelas revistas científicas, de novos procedimentos para o controle da submissão e aceitação do estudo por Comitê de Ética legalmente instituído. Não mais sendo suficiente a declaração de que o estudo foi aprovado pelo Comitê de Ética, geralmente inserida no início da descrição do método do estudo.

Quais são as providências que podem ser tomadas de imediato? O editor da "European Journal of Anaesthesiology", Martin R. Tramèr propôs um novo modelo de apresentação que consiste de um parágrafo, na descrição do método, que contemple: 1- o nome e endereço do responsável pelo Comitê de Ética, 2- o número do protocolo atribuído por esse Comitê, 3- o nome do chefe ou do responsável pela aprovação do protocolo e, 4- a data de aprovação.

Os originais não mais seriam publicados até que esse parágrafo fosse incluído. Isso poderá permitir a rastreabilidade da informação, tanto pelos editores das publicações quanto pelo leitor em geral.

A declaração de potenciais conflitos de interesse deve ser declarada abertamente e de maneira transparente. Não deve ser declarado de maneira lacônica, e sim expor, detalhadamente, o tipo de conflito, por exemplo, citar patrocínio para edição, suprimento de fármacos, análise de dados e preparação do texto.

O caminho está traçado. Basta que se assuma o compromisso de segui-lo.

Ismar Lima Cavalcanti

Membro do Conselho Editorial da Revista Dor-SBED e da Revista Brasileira de Anestesiologia - SBA

Professor Colaborador da Disciplina de Anestesiologia da Faculdade de Medicina da Universidade Federal do Rio de Janeiro - UFRJ Ensino Médico da Coordenação de Ensino e Divulgação Científica do Instituto Nacional de Câncer - INCA 